\title{
Reproductive disorders among cosmetologists and hairdressers: a meta-analysis
}

\author{
Dohyung Kim ${ }^{1} \cdot$ Mo-Yeol Kang ${ }^{1,2} \cdot$ Sungyeul Choi $^{1} \cdot$ Jaechan Park $^{1} \cdot$ Hye-Ji Lee ${ }^{1}$. \\ Eun-A. Kim ${ }^{1}$
}

Received: 15 April 2015 / Accepted: 17 January 2016 / Published online: 28 January 2016

(C) The Author(s) 2016. This article is published with open access at Springerlink.com

\begin{abstract}
Purpose Occupational risks for reproductive disorders among hairdressers and cosmetologists have been examined in numerous epidemiological studies, although the results of those studies have been inconsistent. Therefore, we conducted a meta-analysis of published studies to evaluate the risks of reproductive disorders among cosmetologists and hairdressers.

Methods We searched the MEDLINE, EMBASE, and Cochrane Library databases, as well as the reference lists of relevant publications, to identify studies for our analysis. After careful consideration, 19 eligible studies were included in the meta-analysis. We also performed systematic evaluations of publication bias, heterogeneity, and publication quality.

Results Study-specific odds ratios (ORs) were weighted using the inverse of their variance to calculate fixedand random-effect pooled estimates. The meta-analysis revealed a significantly increased risk of infertility (OR $1.15,95 \%$ CI 1.03-1.28), fetal death (OR 1.14, $95 \%$ CI 1.04-1.24), and preterm delivery (OR 1.04, $95 \%$ CI 1.001.07) among hairdressers and cosmetologists.

Conclusion These findings indicate that hairdressers and cosmetologists have a higher risk of reproductive disorders, compared to the general population.
\end{abstract}

Dohyung Kim and Mo-Yeol Kang have contributed equally to this work.

Eun-A. Kim

toxneuro@gmail.com

1 Occupational Safety and Health Research Institute, 400, Jongga-ro, Jung-gu, Ulsan 681-230, South Korea

2 Department of Preventive Medicine, College of Medicine, Seoul National University, Seoul, South Korea
Keywords Reproductive disorder · Hairdresser . Cosmetologist $\cdot$ Meta-analysis

\section{Introduction}

Cosmetologists are generally defined as individuals who work in retail- or home-based salons and provide a wide range of beauty services, including hair shampooing and styling, manicures, pedicures, and scalp and facial treatments. Hairdressing and cosmetology are common occupations, and several million individuals are employed as hairdressers and cosmetologists (HC) worldwide (European Agency for Safety and Health at Work 2014). Workers in the hairdressing and cosmetology professions are predominantly women, and many of these women are of childbearing age (Halliday-Bell et al. 2009) and begin working before considering family planning (Baste et al. 2008). Therefore, this situation raises concerns that these women of reproductive age could be susceptible to the effects of exposure to potential reproductive toxins.

Hairdressers can be exposed to a variety of chemicals on a daily basis, due to their use of hair products, shampoos, permanent wave solutions, hair dyes, and hair sprays (Labrèche et al. 2003; Jung et al. 2014). Reproductive toxic effects have been reported for some of these agents (Rylander et al. 2002; Rylander and Källén 2005; Pak et al. 2013; Quach et al. 2014), including selenium, some dye formulations, and lead acetate (in animals), in addition to organic solvents, nitrosamines, formaldehyde, dibutyl phthalate, ethylene glycol ethers, and hexachlorophene (in human patients).

In addition to the related chemical agent exposure, work as a $\mathrm{HC}$ consists of prolonged periods of bending and standing, as well as work-related stress, which may have unfavorable effects on reproduction (Strine et al. 2005; 
Palmer et al. 2013). Furthermore, successful hair salons require a "customer-focused" workplace environment, although the customers' needs must be balanced with the understanding that healthy employees provide the best service. Moreover, HC's working hours may vary according to the customers' demands, and a high level of concentration and punctuality is needed to achieve customer satisfaction. The work is also frequently performed at a high pace and under considerable time pressures and other stressful conditions (Ronda et al. 2010). Finally, HC are self-employed with few employees, which can create an environment with limited support for managing workplace health and safety. Taken together, these ergonomic, chemical, and psychosocial factors have generated concern regarding adverse pregnancy outcomes among HC (Kersemaekers et al. 1997).

Several studies of HC have suggested that their work might adversely affect their reproductive health (HerdtLosavio et al. 2009; Ronda et al. 2010; Jørgensen et al. 2013; Quach et al. 2014), although various studies have reported conflicting findings. For example, several studies have reported that $\mathrm{HC}$ have an increased risks of infertility (Baste et al. 2008), a time to pregnancy of $>12$ months (Kersemaekers et al. 1997), spontaneous abortion (Ronda et al. 2010), low birth weight (Halliday-Bell et al. 2009; Herdt-Losavio et al. 2009), and preterm delivery (HallidayBell et al. 2009), compared to women in other occupations or in the general population. However, other studies have found little or no evidence of an increased reproductive health risk among female hairdressers (Hougaard et al. 2006; Gallicchio et al. 2011).

One review article has stated that an increased risk of fertility disorders and pregnancy complications among $\mathrm{HC}$ cannot be excluded (Peters et al. 2010). However, although that study's authors summarized the available evidence regarding fertility disorders and pregnancy complications among HC, they did not perform a comprehensive metaanalysis. Nevertheless, despite the lack of decisive supportive evidence regarding reproductive toxicity among $\mathrm{HC}$, concerns persist regarding their occupation-related safety, especially among pregnant HC. Therefore, we conducted this meta-analysis to determine whether $\mathrm{HC}$ have an increased risk of reproductive disorders, such as small for gestational age (SGA), low birth weight (LBW), infertility, preterm birth, and fetal death.

\section{Methods}

\section{Search strategy}

We searched the MEDLINE, EMBASE, and Cochrane Library databases for studies that reported reproductive disorders among HC between January 1970 and January
2015. The search terms that we used were as follows: "female" or "woman"; "hairdresser" or "hairstylist" or "cosmetologist"; and "spontaneous abortion" or "fetal/ early loss" or "fetal death" or "preterm/perinatal death" or "stillbirth" or "small for gestational age" or "fertility" or "infertility" or "subfertility" or "time to pregnancy" or "preterm delivery" or "low birth weight" or "pregnant/ reproductive disorder." We also manually searched the reference lists of the relevant articles that were obtained from our search. Studies were considered eligible and included in the analysis if they met all of the following criteria: (1) case-control, cohort, or cross-sectional design; (2) reported effect estimates, such as odd ratios (OR) and relative risk (RR) with $95 \%$ confidence interval (CI), or outcome values that allowed for effect estimate calculations in a $2 \times 2$ cell table; and (3) discussed whether the mother's work as a $\mathrm{HC}$ was associated with their adverse pregnancy outcomes. The exclusion criteria were as follows: (1) reported irrelevant outcomes; (2) absence of effect estimates or if we could not calculate the risk; (3) letter, comment, or review article; (4) identical study population; (5) not written in English; and (6) not human subjects. If a study population was duplicated in more than one article, we included only the latest publication after a review of the full text. However, studies were included if different outcome variables were reported, despite the use of identical study populations. Two authors (DK and MK) screened all of the abstracts, reviewed the full texts, and determined eligibility according to the inclusion criteria; discrepancies regarding a study's inclusion were resolved via discussion and consensus.

\section{Bias and confounding variable evaluation}

All included studies adjusted for maternal age as a confounding variable in the final model, but only eight studies adjusted for parity/gravidity, whereas 15 adjusted for maternal smoking. The adjusted confounding variables in the included studies are listed in Table 1 . To control potential selection bias, most studies compared the general characteristics of the study group with a reference group, but four studies did not (Li et al. 2010; Rylander and Källén 2005; McDonald et al. 1987, 1988). To prevent recall bias, some studies compared the answers of the subject's questionnaire with hospital records or birth certificates (HerdtLosavio et al. 2011; Ronda et al. 2010). The potential for recall bias is also indicated in Table 1 .

\section{Quality assessment}

The Newcastle-Ottawa scale (NOS) was used to evaluate the quality of the included studies (Wells et al. 2014). For each study, we rated 9 items using a score of 0 or 1 , and the 


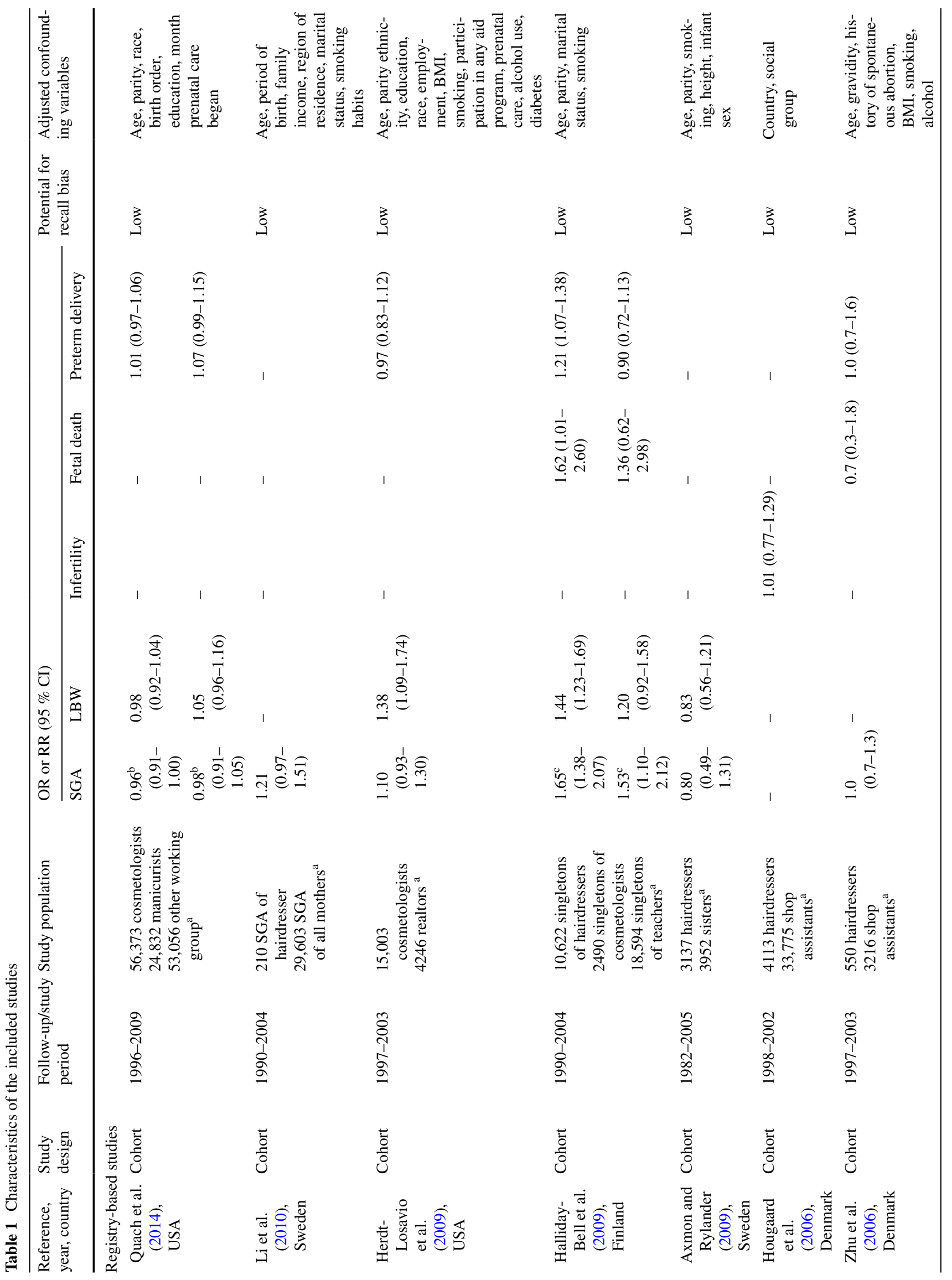




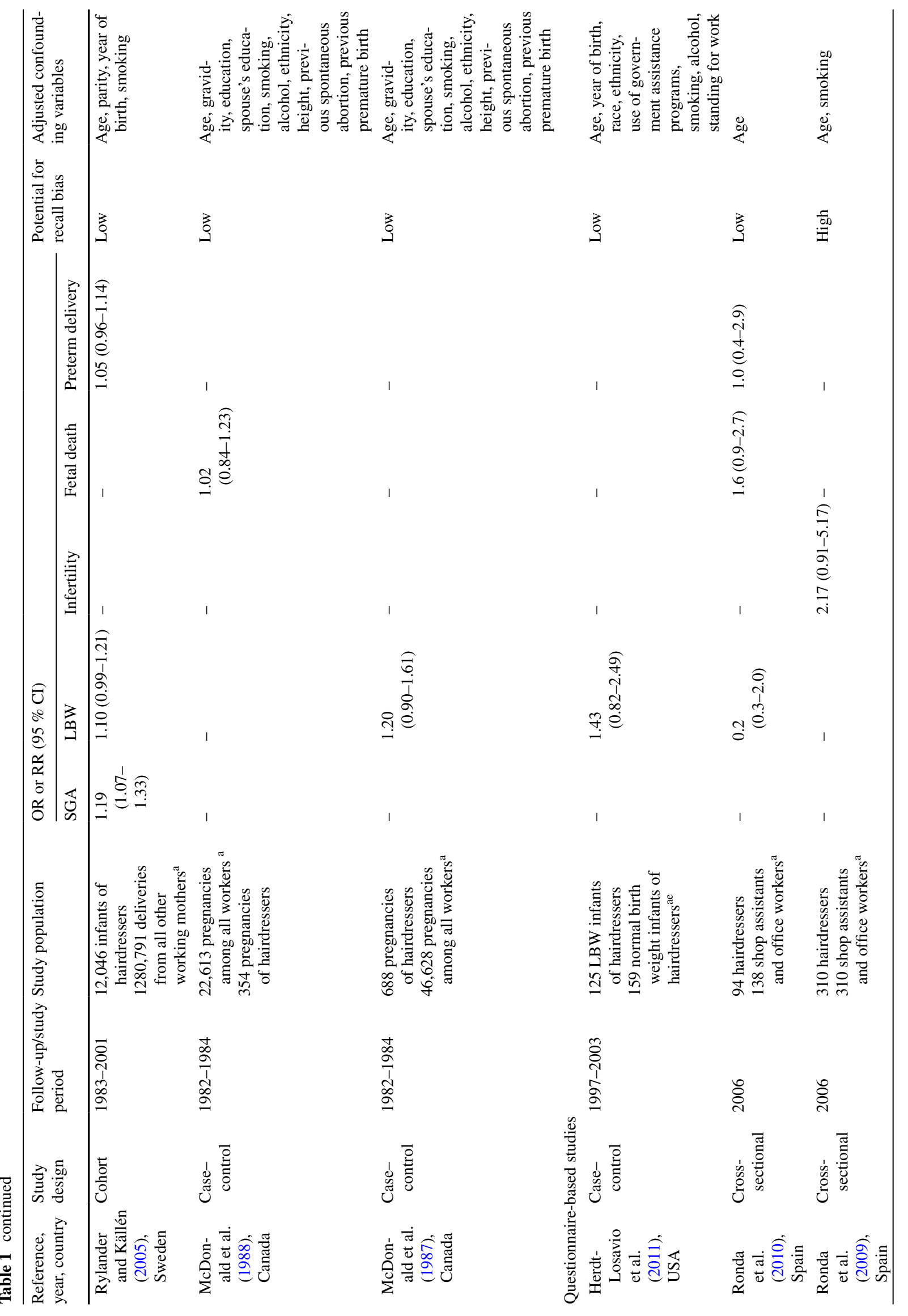




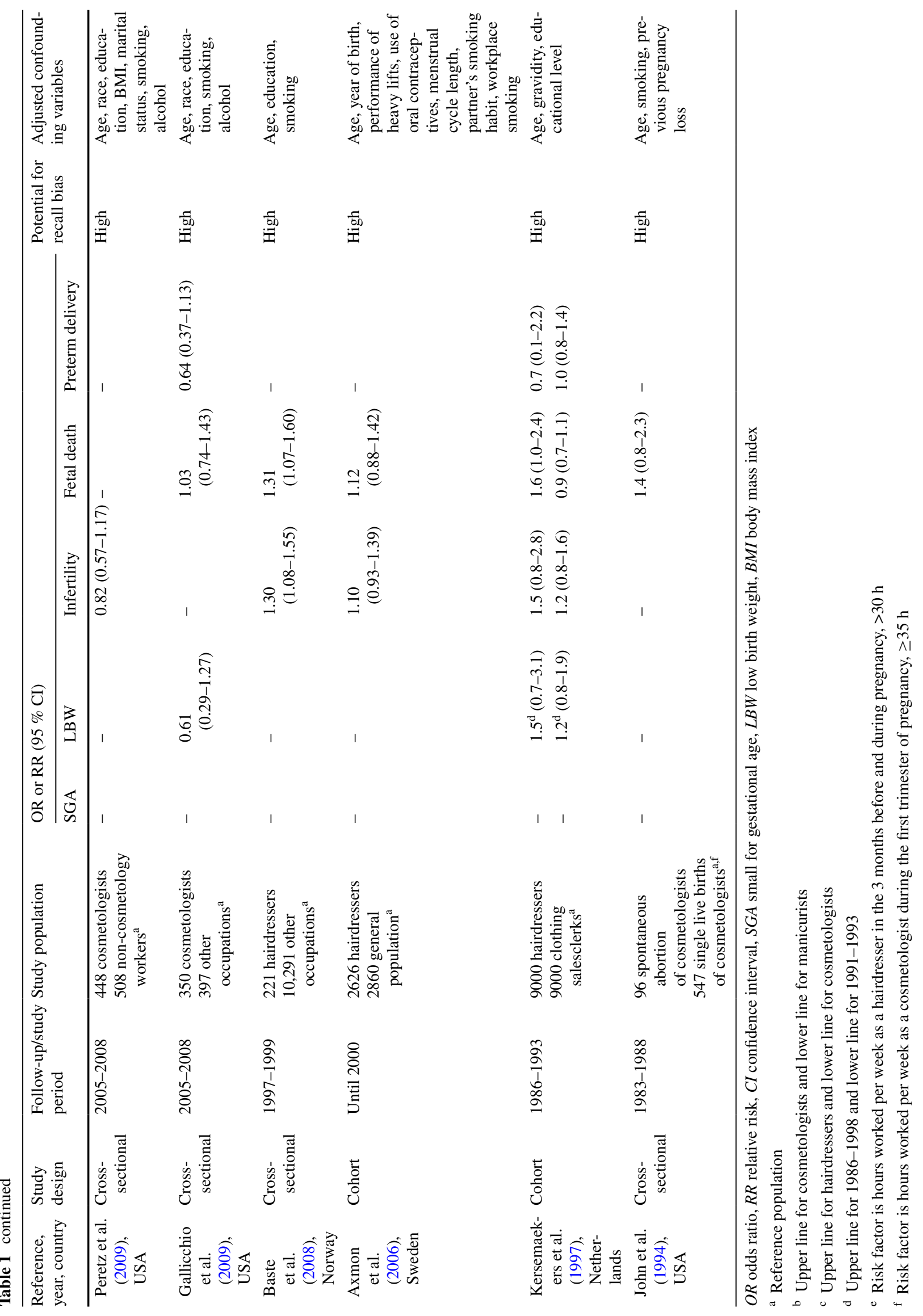


total score was calculated to determine the study's quality (possible range 0-9).

For case-control and cross-sectional studies, this scoring system evaluated 4 items for the selection of cases and controls, 2 items for the comparability of cases and controls, and 3 items to ascertain exposure. For example, item 1 was rated for adequate case definition with independent validation or reference to primary record source, such as medical/hospital records, but not for simple record linkage to a database or self-report. Item 5 was rated for controlling the most important potentially confounding variable (i.e., previous reproductive history); therefore, if a study only analyzed the first pregnancy or used specific statistical methods that dealt with correlated observations, the study could be rated. Item 6 was rated for adjusting the regression model for the second most important confounding variables, such as maternal age and parity/gravidity. Item 7 was rated for quantitative exposure assessment, which was described as working time per week during pregnancy.

For cohort studies, this scoring system evaluated 4 items for the selection of the cohorts, 2 items for comparability, and 3 items for the assessment of outcome. For example, item 3 for ascertainment of exposure was rated only if the study provided quantitative exposure assessment, such as the working time as a hairdresser or cosmetologist during pregnancy. Items 5 and 6 for comparability were the same as those in case-control studies. Item 7 for the assessment of outcome was rated when independent or blind assessment was reported in the paper, or when the outcome was confirmed by reference to medical/hospital records or record linkage to a database. More detailed information regarding how the ratings were applied has been previously reported (Wells et al. 2014).

\section{Data extraction}

The data that we extracted included the data source, study design, authors, publication year, country of origin, data collection period, definition of case-controls or cohorts, types of adverse pregnancy outcome(s), and adjusted effect estimates. Several studies reported effect estimates as observed to expected $(O / E)$ ratios, and we manually calculated the relative risks and confidence intervals using $2 \times 2$ cell tables (Morris and Gardner 1988). All data were extracted exclusively from the published articles, and we did not contact the authors to obtain any additional information. Any data discrepancies were resolved via consensus among the authors.

\section{Statistical analysis}

Our meta-analysis was conducted by grouping studies according to 5 outcomes: SGA, LBW, infertility, preterm delivery, and fetal death. In our analysis, fetal death was defined as intrauterine fetal death, including spontaneous abortion, preterm/perinatal death, or stillbirth. If a study reported the outcomes for two or more different groups that were compared to a common reference group, we estimated the common risks for the different groups, which were calculated using inverse-variance-weighted average. To calculate the overall $\mathrm{OR}$, we attempted to use the outcome results in the final models and the $95 \%$ CI that was described in each study. We also assessed inter-study heterogeneity using Cochran's $Q$ test and Higgins $I^{2}$ statistic. If the $p$ value of the Cochran's $Q$ test was $<0.10$, or if the Higgins $I^{2}$ statistic was $>50 \%$, we concluded that substantial inter-study heterogeneity was present and applied the random-effect (RE) model to calculate the overall OR. If substantial heterogeneity was not present, we used the fixed-effect (FE) model. Supplementary sub-analyses were conducted, in addition to an analysis of registry-based and questionnairebased studies. First, we performed a separate analysis of hairdressers and cosmetologists, as their exposures may not be comparable. Similarly, sub-analyses according to the studies' quality and potential for recall bias were also conducted. Publication bias was tested using Begg's rank correlation test, and Egger's regression test for funnel plot asymmetry. If the $p$ value for either test was $<0.05$, we concluded that publication bias existed. All statistical analyses were performed using R software (version 3.1.2) and the "metafor" package (Viechtbauer 2010).

\section{Results}

Our search retrieved 73 studies from the three databases, as shown in Fig. 1. After screening the titles and abstracts, 50 studies were excluded due to duplication $(n=17)$; irrelevant outcomes $(n=26)$; review, letter, or comment articles $(n=5)$; and non-English language $(n=2)$. After the full-text review, we subsequently excluded 1 study that shared a common study population, 2 studies for which we could not calculate the effect estimates, and 1 study that reported an irrelevant outcome. Therefore, 19 eligible studies were included in the metaanalysis (10 cohort, 6 cross-sectional, and 3 case-control), and their characteristics and quality assessment scores are listed in Tables 1 and 2. We also classified the included studies as registry-based studies, which used national-/state-wide registries to identify reproductive outcomes by linking occupational and medical/birth records, or as questionnaire-based studies, which used in person/mail/telephone questionnaires/interviews to identify reproductive outcomes. 


\section{Small for gestational age}

A total of 7 studies reported the SGA outcome, and all of these studies were registry-based (Fig. 2). The study by Quach et al. (2014) reported the outcomes for two different groups: cosmetologists and manicurists; therefore, we estimated the common risk for those groups. Similarly, we estimated the common risk for the study by Halliday-Bell et al. (2009), because the study reported outcomes for cosmetologists and hairdressers. Substantial heterogeneity was observed $\left(I^{2}=87.15 \%\right.$, Cochran's $Q p$ value $\left.<0.0001\right)$, and we used the RE model to calculate the effect estimates. This analysis revealed an insignificantly increased summary OR of 1.14 (95\% CI 0.97-1.33) for SGA among HC. Begg's test $(p=0.7726)$ and Egger's test $(p=0.5611)$ did not reveal significant publication bias.

\section{Low birth weight}

Eight studies reported the LBW outcome, including 5 registry-based and 3 questionnaire-based studies (Fig. 3). The studies by Quach et al. (2014), Halliday-Bell et al. (2009), and Kersemaekers et al. (1997) reported the outcomes for different groups or study periods: cosmetologists and manicurists, cosmetologists and hairdressers, and 1988-1991 and 1991-1993. Thus, we estimated common risks for each of the studies. Substantial heterogeneity was observed $\left(I^{2}=72.36 \%\right.$, Cochran's $\left.Q p=0.0007\right)$, and we used the RE model for this analysis. The meta-analysis for LBW revealed a $12 \%$ increase in the risk among $\mathrm{HC}$, which was not statistically significant (95\% CI 0.98-1.27). However, the study by Ronda et al. (2010) was excluded from the analysis, because the outcome (OR) was incorrectly outside the confidence interval. We subsequently used Morris and Gardner's (1988) methods to manually include Ronda et al.'s study in the RE model and found that the increased risk was similar to the original result (summary OR 1.11, $95 \%$ CI 0.97-1.26). Subgroup analysis of the registryand questionnaire-based studies also revealed increased risks of LBW among HC (summary ORs 1.11 and 1.17, respectively), which were not statistically significant (95\% CIs $0.97-1.27$ and 0.88-1.56, respectively). Begg's test $(p=1.0)$ and Egger's test $(p=0.6439)$ did not reveal significant publication bias.

\section{Infertility}

Six studies reported the infertility outcome, including 1 registry-based and 5 questionnaire-based studies (Fig. 4). The study by Kersemaekers et al. (1997) reported the outcomes for two different study periods, and we estimated the common risk for that study. No substantial heterogeneity was observed $\left(I^{2}=42.71 \%\right.$, Cochran's $Q p=0.1204$ ), and we used the FE model. Because the study by Axmon et al. (2006) reported the outcome as fecundability (the likelihood of achieving pregnancy), we used the inverse odds ratio to describe the risk of infertility. This analysis revealed a significantly elevated summary OR of 1.15 (95\% CI 1.03-1.28) for infertility among HC. The subgroup analysis for questionnairebased studies also produced a similar value (summary OR $1.18,95 \%$ CI 1.05-1.32). Begg's test $(p=0.7194)$ and Egger's test $(p=0.8893)$ did not reveal significant publication bias.

\section{Fetal death}

Nine studies reported the fetal death outcome, including 3 registry-based and 6 questionnaire-based studies (Fig. 5). The studies by Halliday-Bell et al. (2009) and Kersemaekers et al. (1997) reported outcomes for two different groups or study periods, and we estimated the common risks for each of the studies. The studies were assumed to be homogenous, rather than heterogeneous $\left(I^{2}=20.64 \%\right.$, Cochran's $Q p=0.2594$ ), and we used the FE model. The results revealed a significantly increased risk of fetal death among HC (summary OR 1.14, $95 \%$ CI 1.04-1.24). The subgroup analysis for registry-based studies did not reveal a significantly increased risk (summary OR 1.12, $95 \% \mathrm{CI}$ 0.79-1.59), although the subgroup analysis for questionnaire-based studies did reveal a significantly increased risk (summary OR 1.16, $95 \%$ CI 1.04-1.29). Begg's test $(p=0.4767)$ and Egger's test $(p$ 0.4087) did not reveal significant publication bias.

\section{Preterm delivery}

Eight studies reported the preterm delivery outcome, including 5 registry-based and 3 questionnaire-based studies (Fig. 6). The studies by Quach et al. (2014), HallidayBell et al. (2009), and Kersemaekers et al. (1997) described different exposure groups; therefore, we estimated the common risks for each of the studies. No substantial heterogeneity was observed $\left(I^{2}=0.0 \%\right.$, Cochran's $\left.Q p=0.5065\right)$, and we used the FE model. This analysis revealed a significantly increased summary OR of 1.04 (95\% CI 1.001.07) for preterm delivery among HC. Subgroup analysis of the registry-based studies also revealed an significantly increased risk (summary OR 1.04, $95 \%$ CI 1.00-1.07), although the subgroup analysis of questionnaire-based studies revealed an insignificantly decreased risk (summary OR 0.91, $95 \%$ CI 0.72-1.16). Begg's test $(p=0.9049)$ and Egger's test $(p=0.4416)$ did not reveal significant publication bias. 

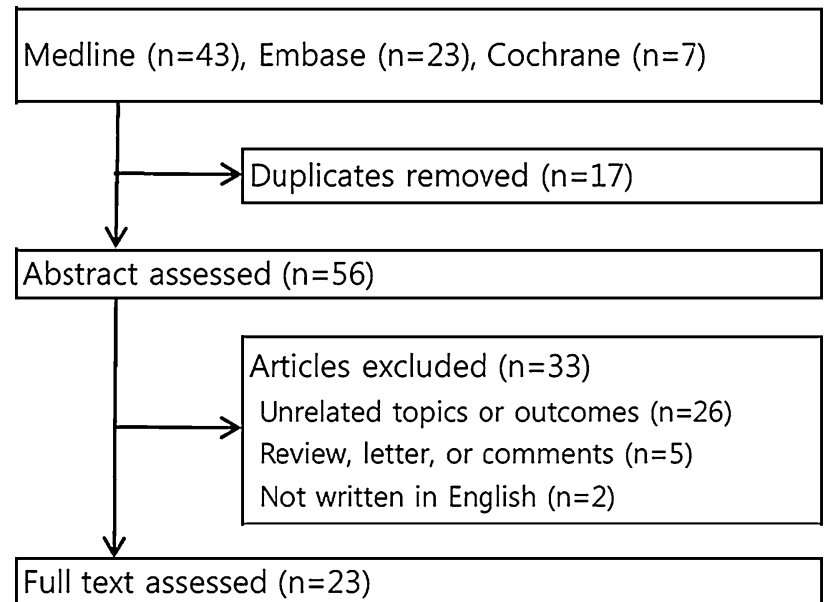

Full text assessed $(n=23)$

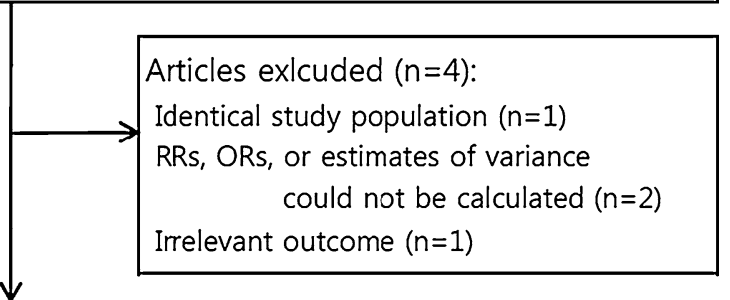

Final analysis $(\mathrm{n}=19)$

Fig. 1 Flow diagram for identifying eligible studies. $R R$ relative risk, $O R$ odds ratio

\section{Subgroup analysis}

Subgroup analyses were performed for occupation (cosmetologist/hairdresser), quality score with a cutoff of 7 , the potential for recall bias, and study type (registry-/questionnaire-based). The manicurists in the study by Quach et al. (2014) were considered cosmetologists, while the study by Halliday-Bell et al. (2009) was evaluated as two separate studies in the occupation analysis. In the study type analysis, the risk for preterm delivery was significantly increased in registry-based studies, whereas those for infertility and fetal death were significantly increased in questionnairebased studies. In the quality score analysis, the risk for preterm delivery was significantly increased in the high score group. In the occupation analysis (hairdresser/cosmetologist), all risks for the five reproductive outcomes were significantly increased in the hairdresser group, whereas those for the four reproductive outcomes were insignificantly increased in the cosmetologist group (Table 3).

\section{Discussion}

To our knowledge, this is the first meta-analysis of epidemiological studies to examine the risk of reproductive disorders among HC. A total of 19 eligible studies were included in our meta-analysis, and the results revealed that these workers had significantly increased risks of various reproductive disorders, including infertility, fetal death, and preterm delivery.

Previous studies have reported that cosmetology or hairdressing is associated with a variety of health issues, including malignancies in lung, larynx, and bladder (Takkouche et al. 2009); asthma (Moscato and Galdi 2006); chronic bronchitis and asthma-like symptoms (Leino et al. 1997; Brisman et al. 2003); and contact dermatitis (Uter et al. 1999; Lee and Nixon 2001; Khumalo et al. 2006; Lind et al. 2007). Nevertheless, no studies have conclusively reported reproductive risks among $\mathrm{HC}$, although SGA, LBW, and spontaneous abortions have been frequently investigated. In addition, other studies have described increased risks of infertility, congenital malformations, SGA, LBW, and cancer during childhood. Furthermore, one systematic review has reported that an increased risk of fertility disorders and pregnancy complications among HC cannot be excluded (Peters et al. 2010), although the risk of reproductive disorders was thought to be low. Similarly, our analysis revealed significantly increased risks of $15 \%$ for infertility, $14 \%$ for fetal death, and $4 \%$ for preterm delivery when we compared $\mathrm{HC}$ to other populations or occupational groups.

The studies that we evaluated used different methodological approaches, which make it difficult to draw a definitive conclusion regarding our findings. For example, it is possible that patients were misclassified in the original studies due to the reliance on recall and that recall bias may have affected our findings, because mothers of children with adverse outcomes may have better recall of exposures, due to their heightened awareness. However, variables such as smoking, drinking, and drug use may be underreported because of the stigma that is associated with these behaviors, especially when the subject is pregnant (Reichman and Hade 2001). Although the time to pregnancy was likely accurately reported by the women (Peretz et al. 2009), the recall regarding work-related factors in the hairdresser cohort may not have been equally good. Nevertheless, if misclassification was introduced via the studies' questionnaires, it may have caused underestimation of the effects of specific exposures. To avoid misclassification of exposure, detailed questions were asked about specific tasks (Herdt-Losavio et al. 2011), and birth certificates were used to validate information that was given by the participants regarding birth weight and certain potential confounders (Rylander and Källén 2005; Zhu et al. 2006; Halliday-Bell et al. 2009; Herdt-Losavio et al. 2009; Li et al. 2010). In our analysis, it is possible that methodological differences affected the results of the analyses, although we performed subgroup analyses for the registry- and questionnairebased studies, which revealed few significant differences. 
Table 2 Quality assessment according to the Newcastle-Ottawa scale

\begin{tabular}{|c|c|c|c|c|c|c|c|c|c|c|}
\hline \multirow[t]{2}{*}{ Eligible studies } & \multicolumn{4}{|c|}{ Selection } & \multicolumn{2}{|c|}{ Comparability } & \multicolumn{3}{|c|}{$\begin{array}{l}\text { Ascertainment of exposure/ } \\
\text { outcome }\end{array}$} & \multirow[t]{2}{*}{ Total score } \\
\hline & Item 1 & Item 2 & Item 3 & Item 4 & Item 5 & Item 6 & Item 7 & Item 8 & Item 9 & \\
\hline \multicolumn{11}{|l|}{ Registry-based } \\
\hline Quach et al. (2014), USA & $*$ & $*$ & & $*$ & & $*$ & * & $*$ & * & 7 \\
\hline Li et al. (2010), Sweden & $*$ & & & $*$ & $*$ & $*$ & $*$ & $*$ & $*$ & 7 \\
\hline Herdt-Losavio et al. (2009), USA & $*$ & $*$ & & $*$ & & $*$ & * & $*$ & * & 7 \\
\hline Halliday-Bell et al. (2009), Finland & $*$ & $*$ & & $*$ & & $*$ & $*$ & $*$ & $*$ & 7 \\
\hline Axmon and Rylander (2009), Sweden & $*$ & $*$ & & $*$ & & $*$ & $*$ & $*$ & $*$ & 7 \\
\hline Hougaard et al. (2006), Denmark & $*$ & * & & $*$ & & & $*$ & $*$ & $*$ & 6 \\
\hline Zhu et al. (2006), Denmark & $*$ & * & $*$ & $*$ & $*$ & $*$ & * & $*$ & $*$ & 9 \\
\hline Rylander and Källén (2005), Sweden & $*$ & & $*$ & & & $*$ & * & $*$ & $*$ & 6 \\
\hline McDonald et al. (1988), Canada & $*$ & $*$ & & & & $*$ & $*$ & $*$ & & 5 \\
\hline McDonald et al. (1987), Canada & $*$ & $*$ & & & & $*$ & $*$ & $*$ & & 5 \\
\hline \multicolumn{11}{|l|}{ Questionnaire-based } \\
\hline Herdt-Losavio et al. (2011), USA & $*$ & * & $*$ & & & $*$ & $*$ & $*$ & $*$ & 7 \\
\hline Ronda et al. (2010), Spain & $*$ & $*$ & $*$ & $*$ & $*$ & $*$ & $*$ & $*$ & $*$ & 9 \\
\hline Ronda et al. (2009), Spain & & $*$ & $*$ & $*$ & & $*$ & $*$ & $*$ & $*$ & 7 \\
\hline Peretz et al. (2009), USA & & $*$ & $*$ & & & & $*$ & * & $*$ & 5 \\
\hline Gallicchio et al. (2009), USA & & $*$ & $*$ & $*$ & * & * & & * & $*$ & 7 \\
\hline Baste et al. (2008), Norway & & $*$ & $*$ & $*$ & & & & $*$ & $*$ & 5 \\
\hline Axmon et al. (2006), Sweden & $*$ & $*$ & & $*$ & $*$ & $*$ & & $*$ & $*$ & 7 \\
\hline Kersemaekers et al. (1997), Netherlands & $*$ & $*$ & $*$ & * & * & * & & $*$ & $*$ & 8 \\
\hline John et al. (1994), USA & & $*$ & $*$ & $*$ & & $*$ & $*$ & $*$ & $*$ & 7 \\
\hline
\end{tabular}

For case-control or cross-sectional studies Item 1: adequate case definition, Item 2: representativeness of the cases, Item 3: selection of controls, Item 4: definition of controls, Item 5: control for the most important factor, Item 6: control for any additional factor, Item 7: ascertainment of exposure, Item 8: same methods of ascertainment for cases and controls, Item 9: non-response rate. For cohort studies: Item 1: representativeness of the exposed cohort, Item 2: selection of the non-exposed cohort, Item 3: ascertainment of exposure, Item 4: outcome was not present at start of the study, Item 5: control for the most important factor, Item 6: control for any additional factor, Item 7: assessment of outcome, Item 8: follow-up long enough for outcome to occur, Item 9: adequacy of follow-up of cohorts

* Positive score for the indicated item

Fig. 2 Forest plot for our metaanalysis of small for gestational age. $C I$ confidence interval, $R E$ random-effect, $O R$ odds ratio, $R R$ relative risk, COMMON common risk estimated
Author, year

Weight OR or RR $[95 \% \mathrm{Cl}]$

Quach et al (COMMON), 2014

Li et al, 2010

Herdt-Losavio et al, 2009

Halliday-Bell et al (COMMON), 2009

Axmon et al, 2009

Zhu et al, 2006

Rylander et al, 2005
$19.25 \% \quad 0.97[0.94,1.01]$

$13.93 \% 1.21[0.97,1.51]$

$15.85 \% 1.10[0.93,1.30]$

$15.68 \% 1.62[1.36,1.92]$

$6.58 \% \quad 0.80[0.49,1.31]$

$10.96 \% 1.00[0.73,1.36$ ]

$17.75 \% 1.19[1.07,1.33]$

RE model for all studies $\left(1^{2}=87.15 \%\right) \quad 100.00 \% \quad 1.14[0.97,1.33]$


Fig. 3 Forest plot for our metaanalysis of low birth weight. $C I$ confidence interval, $R E$ randomeffect, $F E$ fixed-effect, $O R$ odds ratio, $R R$ relative risk, $C O M$ $M O N$ common risk estimated

\begin{tabular}{|c|c|c|c|}
\hline Author, year & & Weight & OR or RR [ $95 \% \mathrm{Cl}]$ \\
\hline \multicolumn{4}{|l|}{ Registry-based studies } \\
\hline Quach et al (COMMON), 2014 & & $24.56 \%$ & $1.00[0.95,1.05]$ \\
\hline Halliday-Bell et al (COMMON), 2009 & $H$ & $19.70 \%$ & $1.37[1.19,1.57]$ \\
\hline Axmon et al, 2009 & $\longmapsto$ & $7.69 \%$ & $0.83[0.56,1.22]$ \\
\hline Rylander et al, 2005 & & $22.05 \%$ & $1.10[0.99,1.22]$ \\
\hline McDonald et al, 1987 & & $11.00 \%$ & $1.20[0.90,1.60]$ \\
\hline RE model for Subgroup $\left(I^{2}=81.03 \%\right)$ & & & $1.11[0.97,1.27]$ \\
\hline \multicolumn{4}{|l|}{ Questionnaire-based studies } \\
\hline Herdt-Losavio et al, 2011 & & $4.39 \%$ & $1.43[0.82,2.49]$ \\
\hline Gallicchio et al, 2009 & & $2.68 \%$ & $0.61[0.29,1.28]$ \\
\hline Kersemaekers et al (COMMON), 1997 & $\stackrel{\longrightarrow}{\longrightarrow}$ & $7.92 \%$ & $1.27[0.87,1.85]$ \\
\hline FE model for Subgroup $\left(1^{2}=45.52 \%\right)$ & & & $1.17[0.88,1.56]$ \\
\hline \multirow[t]{4}{*}{ RE model for all studies $\left(1^{2}=72.36 \%\right)$} & & $100.00 \%$ & $1.12[0.98,1.27]$ \\
\hline & 1 & & \\
\hline & 0.50 & & \\
\hline & Summary OR & & \\
\hline
\end{tabular}

Author, year

Registry-based studies

Hougaard et al, 2006

Questionnaire-based studies

Peretz et al, 2009

Ronda et al, 2009

Baste et al, 2008

Axmon et al, 2006

Kersemaekers et al (COMMON), 1997

FE model for Subgroup $\left(I^{2}=47.21 \%\right)$
Weight $\quad$ OR or RR [ $95 \% \mathrm{Cl}]$

$16.64 \% 1.01[0.78,1.31]$

$8.57 \% \quad 0.82[0.57,1.17]$

$1.47 \% \quad 2.17[0.91,5.17]$

$33.94 \% 1.30[1.09,1.56]$

$27.43 \% 1.10[0.90,1.34]$

$11.94 \% 1.26[0.93,1.71]$

$1.18[1.05,1.32]$

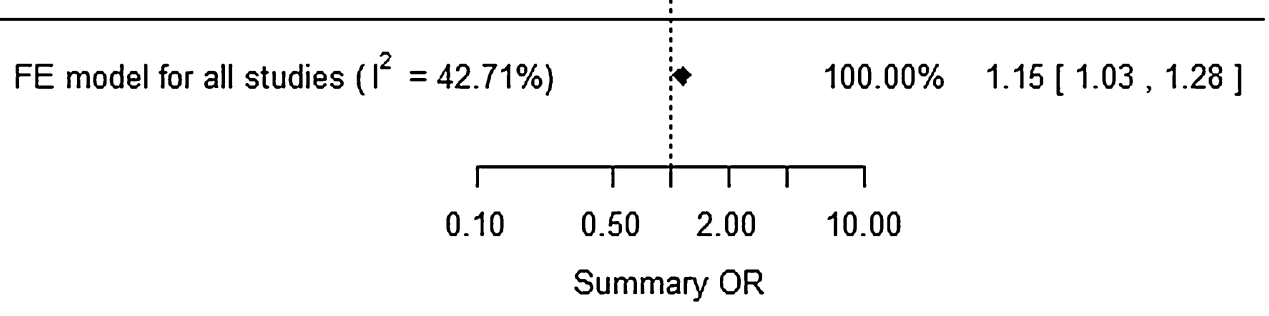

Fig. 4 Forest plot for our meta-analysis of infertility. CI confidence interval, FE fixed-effect, $O R$ odds ratio, $R R$ relative risk, $C O M M O N$ common risk estimated

However, one notable exception was the decreased risk of preterm delivery in the questionnaire-based studies compared to the registry-based studies, although it was not statistically significant.

Another potential source of bias is the use of different reference groups, as the ideal reference group would include women with similar background and working conditions (compared to HC), which would minimize any potential confounding via socioeconomic factors or personal cosmetics use. However, several studies used a single occupational group as the reference group, which included teachers, realtors, shop assistants, and office workers (Halliday-Bell 
Fig. 5 Forest plot for our meta-analysis of fetal death. $C I$ confidence interval, $R E$ randomeffect, $F E$ fixed-effect, $O R$ odds ratio, $R R$ relative risk, $C O M$ $M O N$ common risk estimated
Fig. 6 Forest plot for our metaanalysis of preterm delivery. $C I$ confidence interval, $F E$ fixed-effect, $O R$ odds ratio, $R R$ relative risk, COMMON common risk estimated

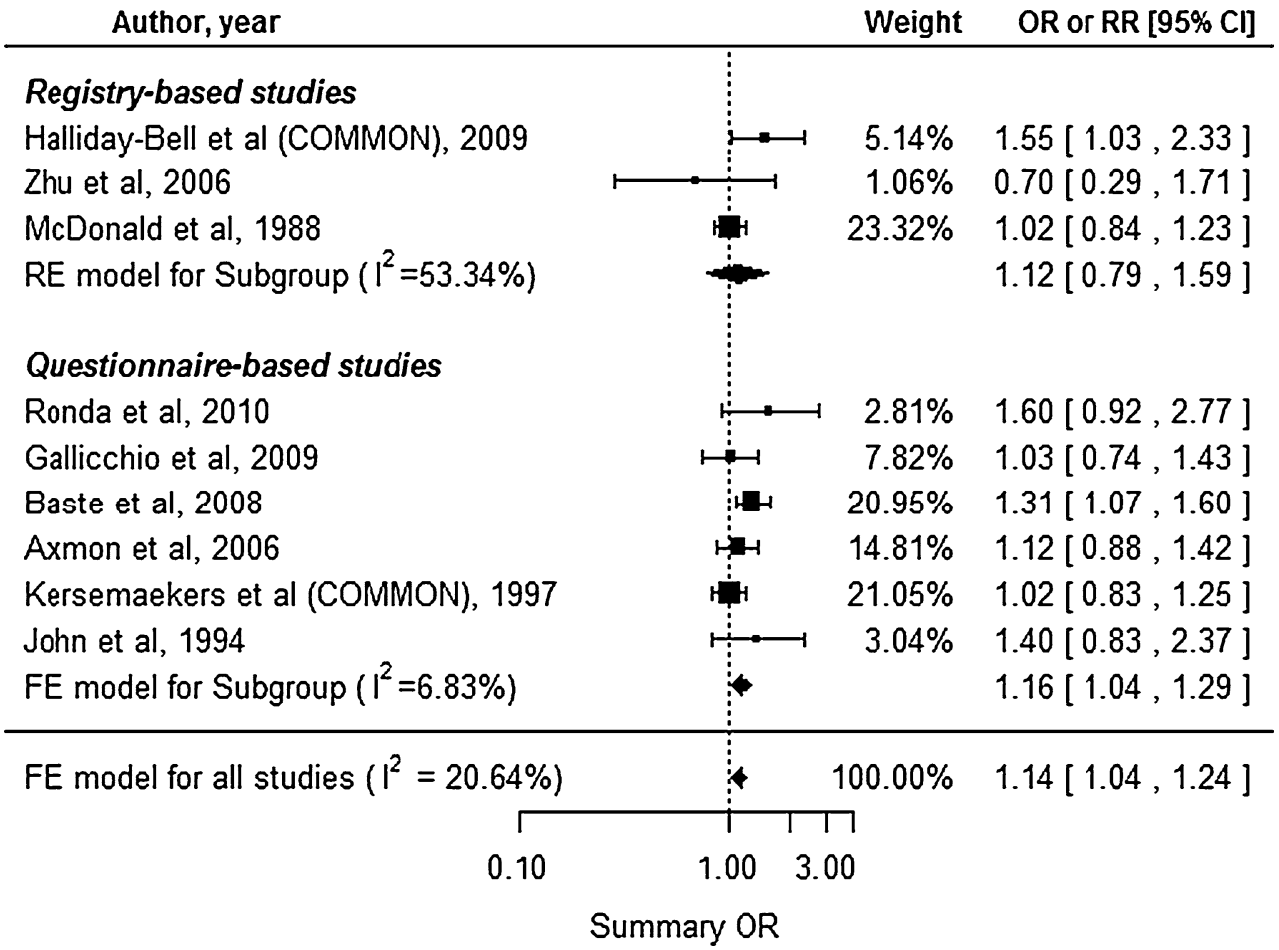

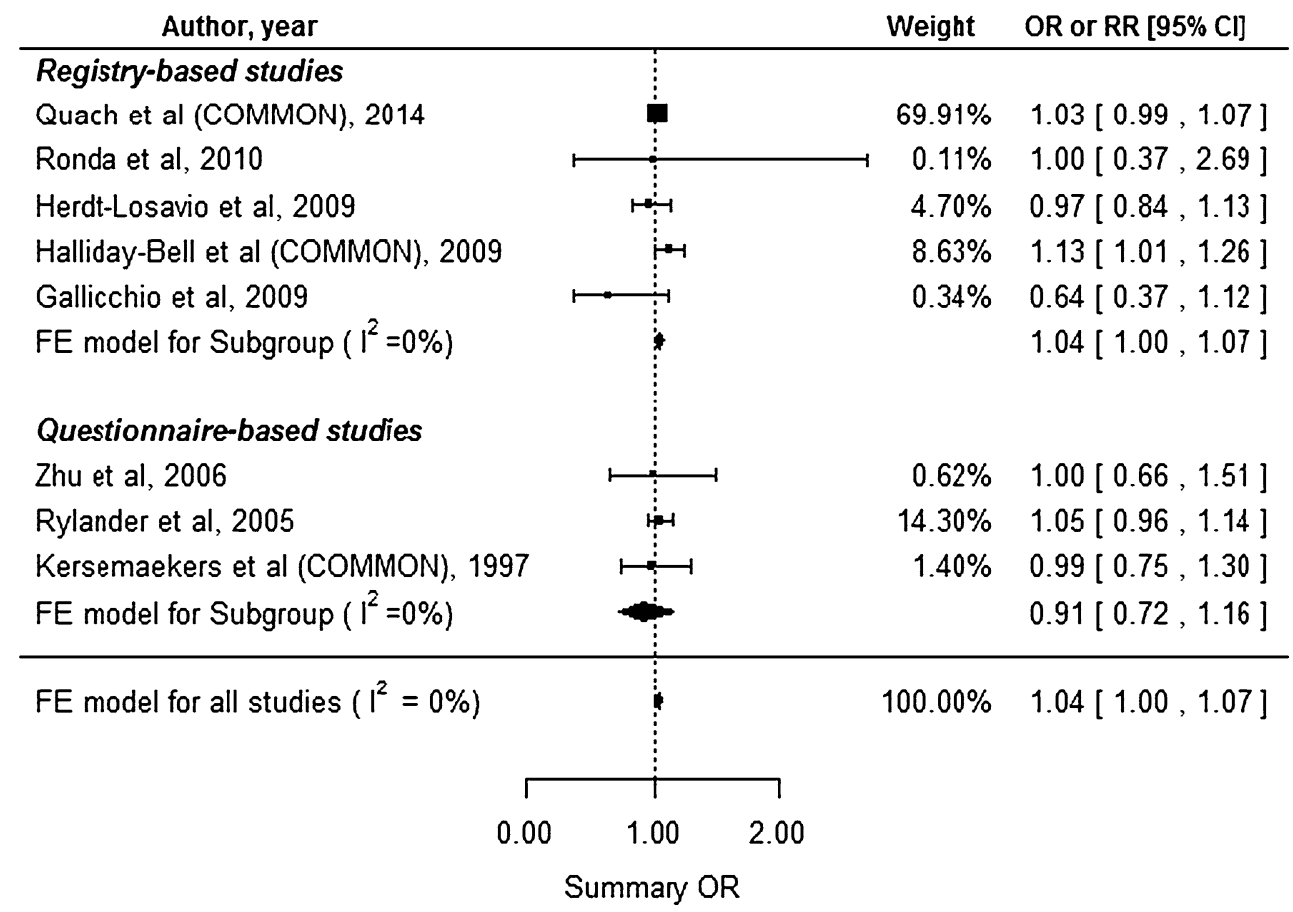

et al. 2009; Herdt-Losavio et al. 2009; Ronda et al. 2010). In contrast, other studies used various occupational groups to provide a more robust comparison to $\mathrm{HC}$ (McDonald et al. 1987, 1988; Axmon and Rylander 2009; Gallicchio et al. 2009; Peretz et al. 2009; Li et al. 2010; Quach et al. 2014). The Swedish studies used all newborns or a sample from the general population (Rylander and Källén 2005; Li et al. 2010), the Dutch study used clothing sales clerks (Kersemaekers et al. 1997), and the Danish study used shop assistants and receptionists (Zhu et al. 2006).

Moreover, job title was used as a proxy for exposure in some studies, although the hairdressing or cosmetology 


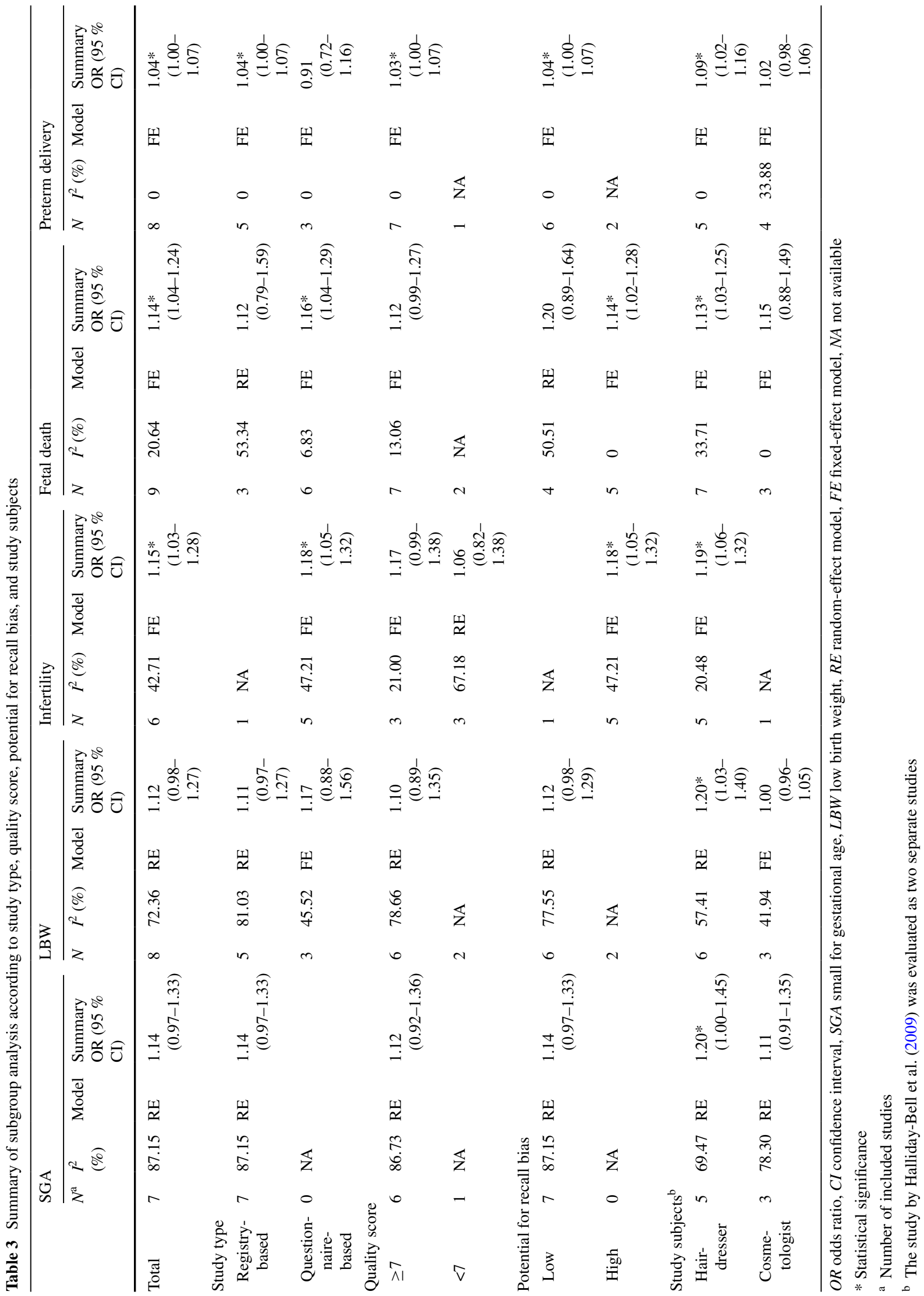


occupations may not be synonymous with exposure to adverse chemicals or work conditions. Exposure assessment is a critical aspect of occupational studies, although the exact assessment techniques can vary for individual studies and range from a simple designation of "cosmetologist" or "hairdresser" as the occupation (McDonald et al. 1987, 1988; Rylander and Källén 2005; Li et al. 2010; Quach et al. 2014) to using questionnaire information for exposure assessment according to task and working hours (e.g., practice vs. shop assistant and office work, and full time vs. part time work) (Hougaard et al. 2006; Zhu et al. 2006; Herdt-Losavio et al. 2011; Ronda et al. 2009, 2010; John et al. 1994), and to differentiation according to the individual hair cosmetic products that are used (Peters et al. 2010). In this context, occupation alone only provides a rough estimation of exposure, and the subsequent risk assessment is likely inaccurate.

Another essential aspect of exposure assessment is the study period, as hairdressers' exposure to chemicals varies widely over different time periods, which complicates measurement and analysis for occupational groups such as hairdressing. However, legislated regulations have led to changes in beauty shops' working environments, such as their sources of exposure and protective facilities. Kersemaekers et al. (1997) assessed the time periods before and after regulatory changes in the Netherlands and reported that the risks of pregnancy complications decreased over time. The authors attributed this decreased risk to the exchange of toxic agents in beauty salons for less hazardous alternatives.

$\mathrm{HC}$ work in a complex environment with several factors that might affect female reproductive function, although chemical exposure has been most frequently mentioned as the cause of reproductive risk among $\mathrm{HC}$ in most studies (Ronda et al. 2010). More than 9000 chemicals are found in cosmetic products (Halliday-Bell et al. 2009), including nitrosamines in hair dye, toluene in nail polish, and phthalates in both hair dye and nail polish (Pak et al. 2013). Exposure to volatile organic compounds (VOCs) such as toluene (inhaled from paint reducer or paint thinner) during pregnancy has adverse effects on the neonate, including intrauterine growth retardation, premature delivery, congenital malformations, and postnatal developmental retardation (Donald et al. 1991). In addition, Peretz et al. (2009) have suggested that environmental exposure to chemicals, such as selenium, ethylene glycol monomethyl ether, and phenylenediamine, may be associated with poor reproductive function and reduced fertility. These chemicals are either inhaled as volatile compounds or absorbed by the skin, as HC often handle them manually. The exposure can accumulate if the products are used daily or if poor ventilation exists in salons (Mendes et al. 2011). Calculations of baseline values for exposure among French hairdressers working in small hairdressing salons revealed that dermal and inhalation exposure can reach 14.68 and $18.1 \mathrm{mg} / \mathrm{kg} /$ day, respectively (Ramirez-Martinez et al. 2015). In a study that was conducted in Italy, products used in hair salons generated an average airborne formaldehyde concentration of $2.4 \mathrm{ppm}$ during heat treatment of hair at $230{ }^{\circ} \mathrm{C}$, and the 8-h exposure level of hairdressers ranged from 0.1 to $0.4 \mathrm{ppm}$, depending on the number of daily treatments (1-4) (Grana et al. 2013). Another study that investigated the chemical exposure level among Portuguese hairdressers revealed that the average concentration of total VOCs was $1.4 \mathrm{mg} / \mathrm{m}^{3}$ above the Portuguese reference level $(0.6 \mathrm{mg} /$ $\mathrm{m}^{3}$ ) and that $4 \%$ of hairdressers had a mean $\mathrm{NH}_{3}$ concentration that was higher than the Portuguese (20 ppm) and American Conference of Governmental Industrial Hygienists (ACGIH) (25 ppm) reference levels (Mendes et al. 2011).

Long working hours and standing throughout the working period have also been associated with higher incidences of spontaneous abortion, SGA, LBW, and preterm birth (Mozurkewich et al. 2000; Bonzini et al. 2007). Palmer et al.'s meta-analysis revealed that an increased risk of preterm delivery was associated with working $>40 \mathrm{~h}$ per week (a $23 \%$ increase) and standing at work for $4 \mathrm{~h}$ per day (a $22 \%$ increase) (Palmer et al. 2013). Exposure to stressful occupational conditions may interfere with a woman's endocrine system, which may explain these adverse reproductive effects (Dole 2003). Another potential explanation for the association between stress and reproductive outcomes (specifically fetal death) is that women who experience high levels of stress are more likely to be smokers (Nelson et al. 2003).

\section{Conclusion}

The results of our meta-analysis suggest that there is a significant increase in the risk of reproductive disorders among $\mathrm{HC}$, compared to the general population or other occupational groups. However, these results should be interpreted within the context of the potential for bias in our findings. Therefore, further studies are needed to evaluate the specific risk factors that are associated with the hairdressing and cosmetology occupations and their adverse effects on reproductive health. In this context, the risk for $\mathrm{HC}$ is low when considered from an absolute perspective, although $\mathrm{HC}$ are common throughout the world and many of them are women who are of reproductive age. Therefore, the 4-15\% risk increase among HC may be important from the public health perspective. These concepts suggest that improvements in occupational health and safety could reduce the considerable incidence of reproductive disorders in this population. To achieve this goal, we believe that 
multi-disciplinary efforts should involve health and safety professionals, epidemiologists, engineers, social scientists, and ergonomists, in order to make $\mathrm{HC}$ a safer occupation.

Funding This study was funded by the Korean Occupational and Safety and Health Agency (Grant Number: 2014-OSHRI-1125).

Author contributions Mo-Yeol Kang and Eun-A Kim conceived and designed the study. Dohyung Kim, Sungyeul Choi, Jaechan Park, and Hye-Ji Lee collected and analyzed the data. Dohyung Kim created the tables and figures. Mo-Yeol Kang, Dohyung Kim, and Eun-A Kim discussed the results and wrote the paper.

\section{Compliance with ethical standards}

Conflict of interest The authors have declared that there are no conflicts of interest, including financial, consultant, institutional, and other relationships that might lead to bias or a conflict of interest.

Open Access This article is distributed under the terms of the Creative Commons Attribution 4.0 International License (http://creativecommons.org/licenses/by/4.0/), which permits unrestricted use, distribution, and reproduction in any medium, provided you give appropriate credit to the original author(s) and the source, provide a link to the Creative Commons license, and indicate if changes were made.

\section{References}

Axmon A, Rylander L (2009) Birth weight and fetal growth in infants born to female hairdressers and their sisters. Occup Environ Med 66:198-204

Axmon A, Rylander L, Lillienberg L, Albin M, Hagmar L (2006) Fertility among female hairdressers. Scand J Work Environ Health 32:51-60

Baste V, Moen BE, Riise T, Hollund BE, Øyen N (2008) Infertility and spontaneous abortion among female hairdressers: the Hordaland Health Study. J Occup Environ Med 50:1371-1377

Bonzini M, Coggon D, Palmer KT (2007) Risk of prematurity, low birthweight and pre-eclampsia in relation to working hours and physical activities: a systematic review. Occup Environ Med 64:228-243

Brisman J, Albin M, Rylander L, Mikoczy Z, Lillienberg L, Höglund AD, Torén K, Meding B, Diab KK, Nielsen J (2003) The incidence of respiratory symptoms in female Swedish hairdressers. Am J Ind Med 44:673-678

Dole N (2003) Maternal stress and preterm birth. Am J Epidemiol 157:14-24

Donald JM, Hooper K, Hopenhayn-Rich C (1991) Reproductive and developmental toxicity of toluene: a review. Environ Health Perspect 94:237-244

European Agency for Safety and Health at Work (2014) Occupational health and safety in the hairdressing sector. https://osha.europa. eu/en/publications/literature_reviews/occupational-health-andsafety-in-the-hairdressing-sector/view. Accessed 7 April 2015

Gallicchio L, Miller S, Greene T, Zacur H, Flaws JA (2009) Cosmetologists and reproductive outcomes. Obstet Gynecol 113:1018-1026

Gallicchio L, Miller SR, Greene T, Zacur H, Flaws JA (2011) Adverse health outcomes among cosmetologists and noncosmetologists in the Reproductive Outcomes of Salon Employees (ROSE) study. J Toxicol Environ Health A 74:52-61
Grana M, Magrini A, Bellieni L (2013) Formaldehyde exposure in a hair salon. Ital J Occup Environ Hyg 4:136-140

Halliday-Bell JA, Gissler M, Jaakkola JJK (2009) Work as a hairdresser and cosmetologist and adverse pregnancy outcomes. Occup Med 59:180-184

Herdt-Losavio ML, Lin S, Druschel CM, Hwang S-A, Mauer MP, Carlson GA (2009) The risk of having a low birth weight or preterm infant among cosmetologists in New York State. Matern Child Health J 13:90-97

Herdt-Losavio ML, Lin S, Druschel CM, Hwang S-A, Mauer MP, Carlson GA (2011) A nested case-control study of low birthweight among cosmetologists. Int Arch Occup Environ Health 84:601-608

Hougaard KS, Hannerz H, Bonde JP, Feveile H, Burr H (2006) The risk of infertility among hairdressers. Five-year follow-up of female hairdressers in a Danish national registry. Hum Reprod 21:3122-3126

John EM, Savitz DA, Shy CM (1994) Spontaneous abortions among cosmetologists. Epidemiology 5:147-155

Jørgensen KT, Jensen MS, Toft GV, Larsen AD, Bonde JP, Hougaard KS (2013) Risk of cryptorchidism and hypospadias among boys of maternal hairdressers-a Danish population-based cohort study. Scand J Work Environ Health 39:302-309

Jung PK, Lee JH, Baek JH, Hwang J, Won JU, Kim I, Roh J (2014) The effect of work characteristics on dermatologic symptoms in hairdressers. Ann Occup Environ Med 26:13. doi:10.1186/2052-4374-26-13

Kersemaekers WM, Roeleveld N, Zielhuis GA (1997) Reproductive disorders among hairdressers. Epidemiology 8:396-401

Khumalo NP, Jessop S, Ehrlich R (2006) Prevalence of cutaneous adverse effects of hairdressing: a systematic review. Arch Dermatol 142:377-383

Labrèche F, Forest J, Trottier M, Lalonde M, Simard R (2003) Characterization of chemical exposures in hairdressing salons. Appl Occup Environ Hyg 18:1014-1021

Lee A, Nixon R (2001) Occupational skin disease in hairdressers. Australas J Dermatol 42:1-6; quiz 7-8

Leino T, Tammilehto L, Paakkulainen H, Orjala H, Nordman H (1997) Occurrence of asthma and chronic bronchitis among female hairdressers. A questionnaire study. J Occup Environ Med Am Coll Occup Environ Med 39:534-539

Li X, Sundquist J, Sundquist K (2010) Parental occupation and risk of small-for-gestational-age births: a nationwide epidemiological study in Sweden. Hum Reprod Oxf Engl 25:1044-1050

Lind M, Albin M, Brisman J, Diab KK, Lillienberg L, Mikoczy Z, Nielsen J, Rylander L, Torén K, Meding B (2007) Incidence of hand eczema in female Swedish hairdressers. Occup Environ Med 64:191-195

McDonald AD, McDonald JC, Armstrong B, Cherry NM, Delorme C, Nolin AD, Robert D (1987) Occupation and pregnancy outcome. Br J Ind Med 44:521-526

McDonald AD, McDonald JC, Armstrong B, Cherry NM, Côté R, Lavoie J, Nolin AD, Robert D (1988) Fetal death and work in pregnancy. Br J Ind Med 45:148-157

Mendes A, Madureira J, Neves P, Carvalhais C, Laffon B, Teixeira JP (2011) Chemical exposure and occupational symptoms among Portuguese hairdressers. J Toxicol Environ Health A 74:993-1000

Morris JA, Gardner MJ (1988) Statistics in medicine: calculating confidence intervals for relative risks (odds ratios) and standardised ratios and rates. Br Med J 296:1313-1316

Moscato G, Galdi E (2006) Asthma and hairdressers. Curr Opin Allergy Clin Immunol 6:91-95

Mozurkewich EL, Luke B, Avni M, Wolf FM (2000) Working conditions and adverse pregnancy outcome: a meta-analysis. Obstet Gynecol 95:623-635 
Nelson DB, Grisso JA, Joffe MM, Brensinger C, Shaw L, Datner E (2003) Does stress influence early pregnancy loss? Ann Epidemiol 13:223-229

Pak VM, Powers M, Liu J (2013) Occupational chemical exposures among cosmetologists: risk of reproductive disorders. Workplace Health Saf 61:522-528; quiz 529

Palmer KT, Bonzini M, Harris EC, Linaker C, Bonde JP (2013) Work activities and risk of prematurity, low birth weight and preeclampsia: an updated review with meta-analysis. Occup Environ Med 70:213-222

Peretz J, Gallicchio L, Miller S, Greene T, Zacur H, Flaws JA (2009) Infertility among cosmetologists. Reprod Toxicol 28:359-364

Peters C, Harling M, Dulon M, Schablon A, Torres Costa J, Nienhaus A (2010) Fertility disorders and pregnancy complications in hairdressers-a systematic review. J Occup Med Toxicol 5:24

Quach T, Von Behren J, Goldberg D, Layefsky M, Reynolds P (2014) Adverse birth outcomes and maternal complications in licensed cosmetologists and manicurists in California. Int Arch Occup Environ Health. doi:10.1007/s00420-014-1011-0

Ramirez-Martinez A, Granda-Torres P, Wesolek N, Ficheux AS, Roudot AC (2015) Exposure of hairdressers to the main cosmetics used in hairdressing salons from France by means of a preliminary study. Arch Environ Occup Health. doi:10.1080/19338244. 2015.1024390. http://www.tandfonline.com/doi/full/10.1080/19 338244.2015.1024390

Reichman NE, Hade EM (2001) Validation of birth certificate data. A study of women in New Jersey's HealthStart program. Ann Epidemiol 11:186-193

Ronda E, García AM, Sánchez-Paya J, Moen BE (2009) Menstrual disorders and subfertility in Spanish hairdressers. Eur J Obstet Gynecol Reprod Biol 147:61-64
Ronda E, Moen BE, García AM, Sánchez-Paya J, Baste V (2010) Pregnancy outcomes in female hairdressers. Int Arch Occup Environ Health 83:945-951

Rylander L, Källén B (2005) Reproductive outcomes among hairdressers. Scand J Work Environ Health 31:212-217

Rylander L, Axmon A, Torén K, Albin M (2002) Reproductive outcome among female hairdressers. Occup Environ Med 59:517-522

Strine TW, Chapman DP, Ahluwalia IB (2005) Menstrual-related problems and psychological distress among women in the United States. J Womens Health (Larchmt) 14:316-323

Takkouche B, Regueira-Mendez C, Montes-Martinez A (2009) Risk of cancer among hairdressers and related workers: a meta-analysis. Int J Epidemiol 38:1512-1531

Uter W, Pfahlberg A, Gefeller O, Schwanitz HJ (1999) Hand dermatitis in a prospectively-followed cohort of hairdressing apprentices: final results of the POSH study. Prevention of occupational skin disease in hairdressers. Contact Dermat 41:280-286

Viechtbauer W (2010) Conducting meta-analyses in R with the metafor package. J Stat Softw 36:1-48

Wells GA, Shea B, O'Connell D, Peterson J, Welch V, Losos M, Tugwell P (2014) Newcastle-Ottawa Scale for assessing the quality of nonrandomised studies in meta-analyses. http://www.ohri.ca/ programs/clinical_epidemiology/oxford.asp. Accessed 22 Jan 2015

Zhu JL, Vestergaard M, Hjollund NH, Olsen J (2006) Pregnancy outcomes among female hairdresser who participated in the Danish National Birth Cohort. Scand J Work Environ Health 32:61-66 